\title{
Design and Speed Control of SynRM Using Cascade PID Controller with PSO Algorithm
}

\author{
Mohammed Ayad Alkhafaji ${ }^{a, b^{*}}$, Yunus Uzun ${ }^{c}$
}

\author{
${ }^{a}$ Department of Electrical Electronic Engineering, Karabuk University, Turkey \\ ${ }^{b}$ Thi-Qar University, Iraq \\ ${ }^{c}$ Department of Electrical and Electronics Engineering, Aksaray University, Turkey
}

\begin{abstract}
In recent years, the variable speed motor drive is supported over a fixed speed motor drive as per essentialness safeguarding, speed or position control and improvement of transient response characteristics. The aim of any speed controller is to take main signal that represent the reference speed and to drive the framework at that reference speed. This paper exhibits the design, simulation and control of synchronous reluctance motor (SynRM). In addition, the motor speed is controlled by utilizing a conventional PID controller that has been used from the cascaded structure. The Particle Swarm Optimization (PSO) was used to find the best parameters of the PID controller. Lead-Lag controller presents from the cascaded controller as the following period of control. The Space vector pulse width modulation (SVPWM) plot has been proposed to control the motor and make the motor work with no rotor confine contingent upon the info parameters that utilization in the simulation. An examination between both of PID tuned and PSO tuned controller affirms that the PSO gives dazzling control highlights to the motor speed and have an edge over the physically changing controller. Thus, this paper present investigation and simulation for the most precise procedures to control the speed reaction and torque reaction of synchronous reluctance motor (SynRM). (O2020. CBIORE-IJRED. All rights reserved
\end{abstract}

Keywords: SynRM, PID, Cascade Controller, PSO, SVPWM, Matlab Environment.

Article History: Received: Oct 16, 2019; Revised: January 7, 2020; Accepted: February 5, 2020; Available online: February 15, 2020

How to Cite This Article: Alkhafaji, M.A., and Uzun, Y. (2020) Design and Speed Control of SynRM using Cascade PID Controller with PSO Algorithm. International Journal of Renewable Energy Development, 9(1), 69-76.

https://doi.org/10.14710/ijred.9.1.69-76

\section{Introduction}

In recent years, a wide variety of synchronous machines are produced. These machines can be used in industry as motor and compensator, energy generation as generator (Hansen \& Michalke 2008; Adlya \& Huzayyin 2019; Bayındır \& Vadi 2017). Particularly because of their high efficiency, there is increasing interest in synchronous machines (Bouloukza et al 2018). SynRM is consider as one of the synchronous machine types has no magnetic parts or any winding in the rotor construction. When contrasted with different synchronous machine SynRM is extremely rough and simple in structure. Before all else, the SynRM was sub-par when contrasted with another kind of motors, for example, induction motor (IM), brushless DC (BLDC) motor, switch hesitance motor (SRM) and DC motor as a result of low normal torque, bigger torque throb and poor power factor. The stator winding of SynRM is same as IM but the rotor structure varies from that. As of late, a noteworthy advancement has been made in the rotor structure to conquer these disservices to empower the SynRM to give a truly steady act. SynRM is a three-stage motor with rotor made of steel axially overlaid hindrances to defeat the low torque and poor power factor attributes (Alkhafaji \& Uzun, 2018). The optimization strategy is utilized in rotor structure configuration to have high quadrature axis hesitance and low direct axis hesitance. Figures 1 demonstrates the mechanical design contents of IM and SynRM and shows the different between them. Since the features of the SynRM makes the motor rough, simple in structure, most minimal expense of assembling prerequisite, high torque per unit volume plausibility and working at extremely high speeds ability. The SynRM has disregarded rotor windings loses there for result simple control techniques and the misfortunes minimization make SynRM an alluring and acclaimed decision for various mechanical and car applications (Fellani \& Abaid 2013; Consoli et al 1999; Fratta \& Vagati 1992). The SynRMs does not have a beginning torque so by utilizing the new kinds of inverters, field orientation control (FOC) innovation and the utilizing of pulse width modulation (PWM) strategy give a truly reasonable procedure to the motor beginning (Fellani $\&$ Abaid, 2010). Lately, the variable speed motor drive is thrown over a fixed speed motor drive because of vitality preservation, speed or position control and improvement

\footnotetext{
* Corresponding author: eng.mark30@gmail.com
} 
of transient reaction attributes. These controllers are utilized to control the speed of the SynRM dependent on three stages Versus SVI procedure and the stationary casing change. SynRm can appear from it is d-q stationary axis identical circuits as in Figures 2. Contingent upon the shut circle speed control frameworks a quick reaction can be acquired. In this paper, the customary PID in fell structure with the lead-slack controller is proposed. PSO procedure is utilized to locate the optimal parameters of the controller parameters. An examination has been made between the physically tuning and the PSO tuning and the outcomes are talked about quickly next.

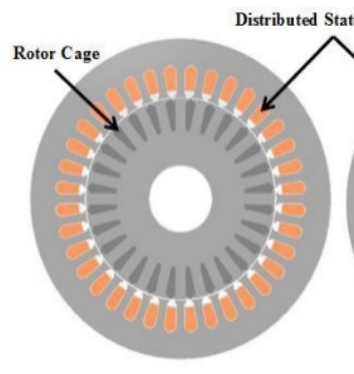

(a)

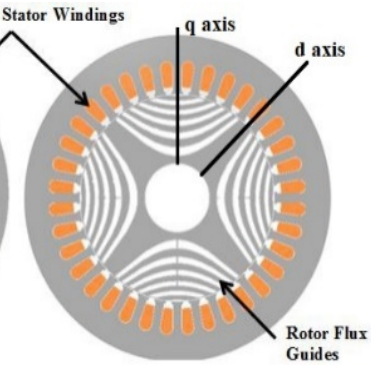

(b)
Fig. 1 The mechanical design contents of (a) IM and (b) SynRM.
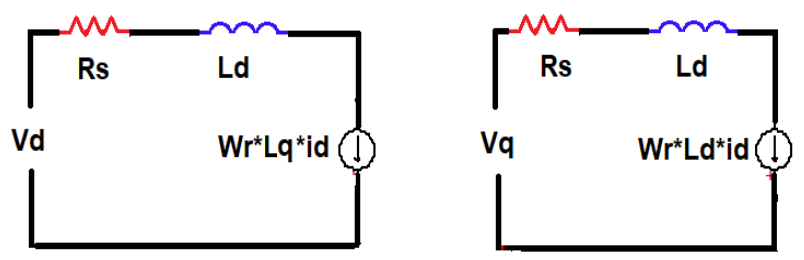

Fig. 2 SynRM d-q axis equivalent circuits

\section{SynRM Mathematical Model}

Three phase SynRM model is perfect for analyzing motor under different operation conditions, but for appropriate control action, the three-phase analysis is rarely used. Besides, the two-axis SynRM model is mainly used for the control synthesis (Fellani \& Abaid 2013; Ma Fellani \& Abai 2010).

$$
\begin{aligned}
V_{d} & =\mathrm{R}_{s} \mathrm{I}_{\mathrm{d}}+\frac{\mathrm{d} \lambda_{d}}{d t}-\omega_{r} \lambda_{q} \\
V_{q} & =\mathrm{R}_{s} \mathrm{I}_{\mathrm{q}}+\frac{\mathrm{d} \lambda_{q}}{d t}+\omega_{r} \lambda_{d} \\
\lambda_{\mathrm{d}} & =\mathrm{L}_{\mathrm{d}} \mathrm{I}_{\mathrm{d}} \\
\lambda_{\mathrm{q}} & =\mathrm{L}_{\mathrm{q}} \mathrm{I}_{\mathrm{q}}
\end{aligned}
$$

The flux rate of change can be obtained as will be shown in equation (5) and (6) as follow.

$$
\begin{gathered}
\frac{\mathrm{d} \lambda_{\mathrm{d}}}{\mathrm{dt}}=\mathrm{V}_{\mathrm{d}}-\mathrm{R}_{\mathrm{s}} \mathrm{I}_{\mathrm{d}}+\omega_{\mathrm{r}} \lambda_{\mathrm{q}} \\
\frac{\mathrm{d} \lambda_{\mathrm{q}}}{\mathrm{dt}}=\mathrm{V}_{\mathrm{q}}-\mathrm{R}_{\mathrm{s}} \mathrm{I}_{\mathrm{q}}-\omega_{\mathrm{r}} \lambda_{d}
\end{gathered}
$$

Besides, by equation (5) the rate of change of direct axis current can obtained in equation (7)

$$
\frac{\mathrm{dI}}{\mathrm{dt}}=\frac{1}{\mathrm{~L}_{\mathrm{d}}}\left(\mathrm{V}_{\mathrm{d}}-\mathrm{R}_{\mathrm{s}} \mathrm{I}_{\mathrm{d}}+\omega_{\mathrm{r}} \mathrm{L}_{\mathrm{q}} \mathrm{I}_{\mathrm{q}}\right)
$$

In addition, by equation (6) the rate of change of quadratic axis current can obtained in equation (8).

$$
\frac{\mathrm{dI}_{\mathrm{q}}}{\mathrm{dt}}=\frac{1}{L_{q}}\left(\mathrm{~V}_{\mathrm{q}}-\mathrm{R}_{\mathrm{s}} \mathrm{I}_{\mathrm{q}}+\omega_{\mathrm{r}} \mathrm{L}_{d} I_{d}\right)
$$

The electromagnetic torque equation for SynRM can be obtained as follow in equation (9).

$$
\mathrm{T}_{e}=\frac{3}{4} \frac{\mathrm{P}}{2}\left(\mathrm{~L}_{\mathrm{d}}-\mathrm{L}_{\mathrm{q}}\right) \mathrm{I}_{\mathrm{d}} \mathrm{I}_{\mathrm{q}}
$$

The total torque equation is given below in equation (10).

$$
\mathrm{T}=\frac{3}{2} P\left(L_{d}-L_{q}\right) i_{d} i_{q}-\left(B \omega_{r}+J \frac{d \omega r}{d t}\right)-\mathrm{T}_{L}
$$

\section{The Speed Control of SynRM}

The speed control of SynRM is so necessary and considers as an important part of these applications which dependent on this type of electric motors. Different techniques are used for speed control of synchronous reluctance motors. This study will focus on two important control topologies. The first is cascade control system, which consists of two or more controllers working together. In this system, the output of the master controller is the set point for the slave controller. The other is Particle Swarm Optimization (PSO) control system, which one particle in the flock makes a move between its local best value and global best value at each refresh. In this way, it approaches the target a little more at each stage and reaches the optimum result after a certain renewal. In the initialization phase, all particle values are generated with random values. Each topology is described below.

\subsection{Cascade Control System}

The processes that have more than one variable at the output. And that should be controlled are well-known as multi-input, multi-output (MIMO) or multivariable processes. Interactions usually exist or sometimes not exist between the control loops of multivariable processes, which is famed by difficulties in control when compare it with the control of single-input, single output (SISO) processes. This type of control process is shown in Figure 3.

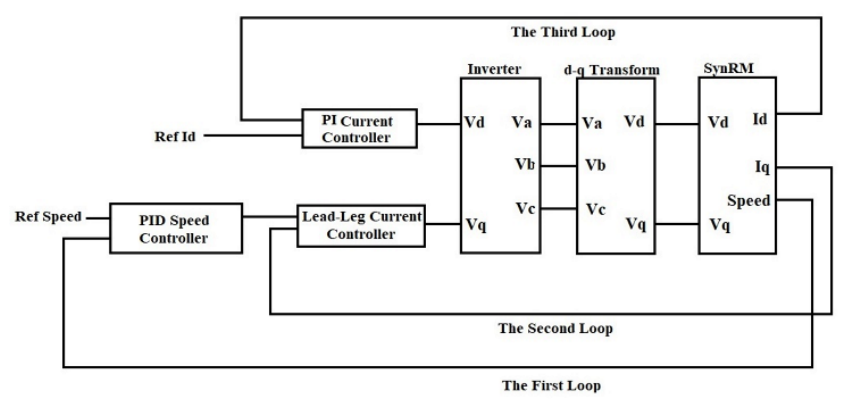

Fig. 3 Cascade controller scheme

The disadvantages of this type of control an exiguity of flexibility for interaction and when comparing it with general multivariable control it has a few powerful tools 
for its design. SISO PID controller is tuned by control engineers, there is one simple way to tune a multi-loop PID controller by first tuning each individual loop one by one, and totally discarding the loop interactions and that is done by tune the (i) loop of cascade controller for the plant transfer. Then re-tuning all the loops together so that the overall system has stable performance and gives an acceptable load disturbance responses (Huang et al 2003; Rahimian \& Raahemifar 2011). Figures 3 shows cascade controller scheme in Matlab/Simulink.

Moreover, the lead-lag compensators are used as a second stage after the PID controller to give advance phase margin and used to control the quadrature axis current to make the system have advanced stabilized performance because it is considered a cascaded lead compensator. The double lead compensator gives double of the phase advance that a simple lead compensator that gives. The double lead compensator mathematical description can be given in equations (7) (Soni and Bhatt 2013).

$$
G(s)=\frac{K\left(1+^{S} / \omega_{z}\right)^{2}}{\left(1+^{S} / \omega_{p}\right)^{2}}
$$

\subsection{Particle Swarm Optimization Tuning PID Controller Parameter}

Particle swarm optimization (PSO) is a public rely on computational approaches that the primary concept came in the simulation of social behavior (social-psychological methods) fish instruction, bird flocking and swarm concept. PSO was initially designed and evolved by Eberhart and Kennedy (Effatnejad et al. 2013; Rambabu et al 2011). This concept was designed to be effective in solving problems exhibiting the non-linearity and the nondifferentiability. The scheme is obtained from study research on swarms such as fish instruction and bird flocking. Accommodation to the results of research for a flock of birds finds that birds food by flocking (not by each individual). Instead of using the evolutionary proses such as mutation and crossover that been used for algorithms manipulation. In the PSO algorithm none of these presses are used, the dynamics of the population simulates a "fish flocks" attitude, where sociably sharing of information takes the major part of work and individuals can profit for discovering and former experience of all the other escorts during the food searching process. The fitness function is cast to maximize the constrains domain or to minimize the preference constraints. The most common performance criteria. that depends on the error criterion are Integrated Absolute Error (IAE), Integrated of Time weight Square Error (ITSE) and Integrated of Square Error (ISE) that can be calculated analytically in the frequency domain. The criteria selection depends on the system and the controller (Effatnejad et al 2013; Rambabu et al 2011). In this paper the fitness functions are used depend on the Integral Squared Error (ISE) criterion.

The local best place is known as $\left(l_{\text {best }}\right)$ refers to some other particle that provides the best swarm position, which contains the minimal fitness value. In addition to, the international best location is known as $\left(g_{\text {best }}\right)$ refers to the very best particle index of particles in a populace. Based on the optimization issue each particle performance has quantified by upgrading its corresponding fitness function. The PSO algorithm structure is shown below on the flowchart in figure 4 . The velocity $\mathrm{v}_{\mathrm{i}}(\mathrm{t})$ and the current position $\mathrm{x}_{\mathrm{i}}(\mathrm{t})$ updating for each particle in the swarm are done in equations $(8,9)$. The velocity of each agent can be updated by the following equation.

$\mathrm{v}_{\mathrm{i}}^{\mathrm{k}+1}=\mathrm{w} * \mathrm{v}_{\mathrm{i}}^{\mathrm{k}}+\mathrm{c}_{1} * \mathrm{R}_{1} *\left(\right.$ lbest $\left._{\mathrm{i}}-\mathrm{x}_{\mathrm{i}}^{\mathrm{k}}\right)+\mathrm{c}_{2} * \mathrm{R}_{2} *\left(\right.$ gbest $\left._{\mathrm{i}}-\mathrm{x}_{\mathrm{i}}^{\mathrm{k}}\right)$

Besides, the current position can be updated by the following equation:

$$
x_{i}^{k+1}=x_{i}^{k}+v_{i}^{k+1}
$$

where $x_{i}^{k}$ is the current position of particle $i$ at iteration $k$, $v_{i}^{k}$ is the velocity of particle $i$ at iteration $k, w$ is the inertia weight which can be shown in equation (10), $c_{1}, c_{2}$ represent positive acceleration constants and $R_{1}, R_{2}$ are random variables distributed uniformly in the range $[0 ; 1]$.

$$
\mathrm{w}=\mathrm{w}_{\max }-\frac{\left(\mathrm{w}_{\max }-\mathrm{w}_{\min }\right)}{\text { iter }_{\max }}
$$

The general flowchart form for PSO algorithm shows in Figure 4.

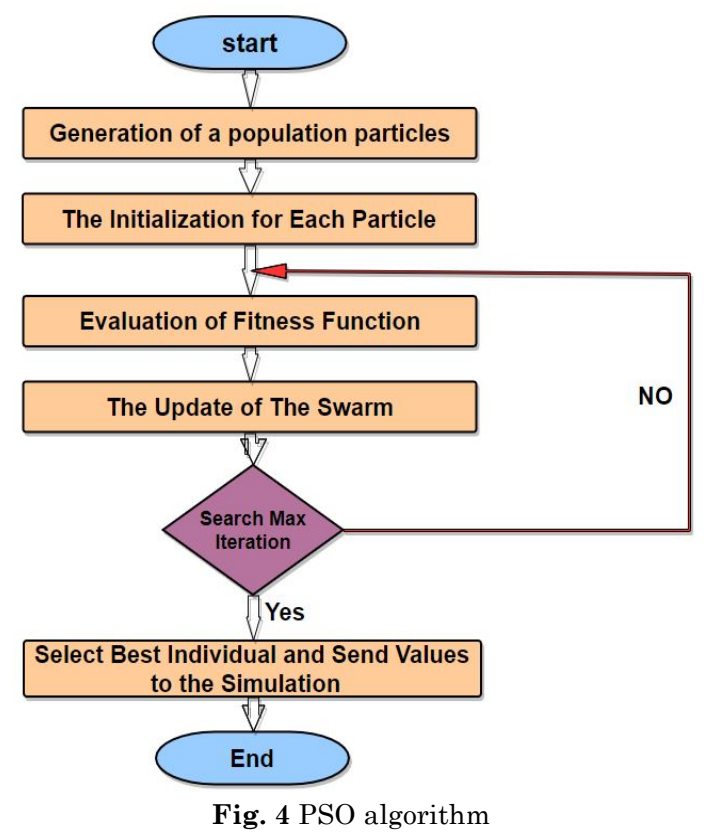

\section{System Simulation and Results}

This section presents simulation results for the SynRM drive. The motor drive system with vector control method has been simulated using Matlab/Simulink environment packages. Figure 4 shows a general flowchart form for PSO algorithm. The drive system and the controller system are shown in Figure 5. The cascade controller has a parameter shown in Table 1, which are found by trial and error and the response due these parameters. Table 2 shows the parameters of cascade controller that been found depending on PSO algorithm. Table 3 shows PID parameter for PSO tuned system. Table 4 shows the output result values of SynRM motor, which used in the control simulations.

The dynamic responses for the motor obtained as shown in Figures 6-8 which are the motor direct axis, quadrature axis currents, speed and torque. Figure 9 shows the obtained speed values for both of controller systems. The obtained torque graph at 1000 RPM speed 
from cascade and PSO tuned systems is shown in Figure 10 .

Figures 11 and 12 show speed and torque values versus the time for $1000 \mathrm{RPM}$ reference and $10 \mathrm{~N}$ load at $0.8 \mathrm{sec}$ applied to cascade and PSO tuned controllers.
Figures 13 and 14 show the speed and torque responses for different step reference speed.

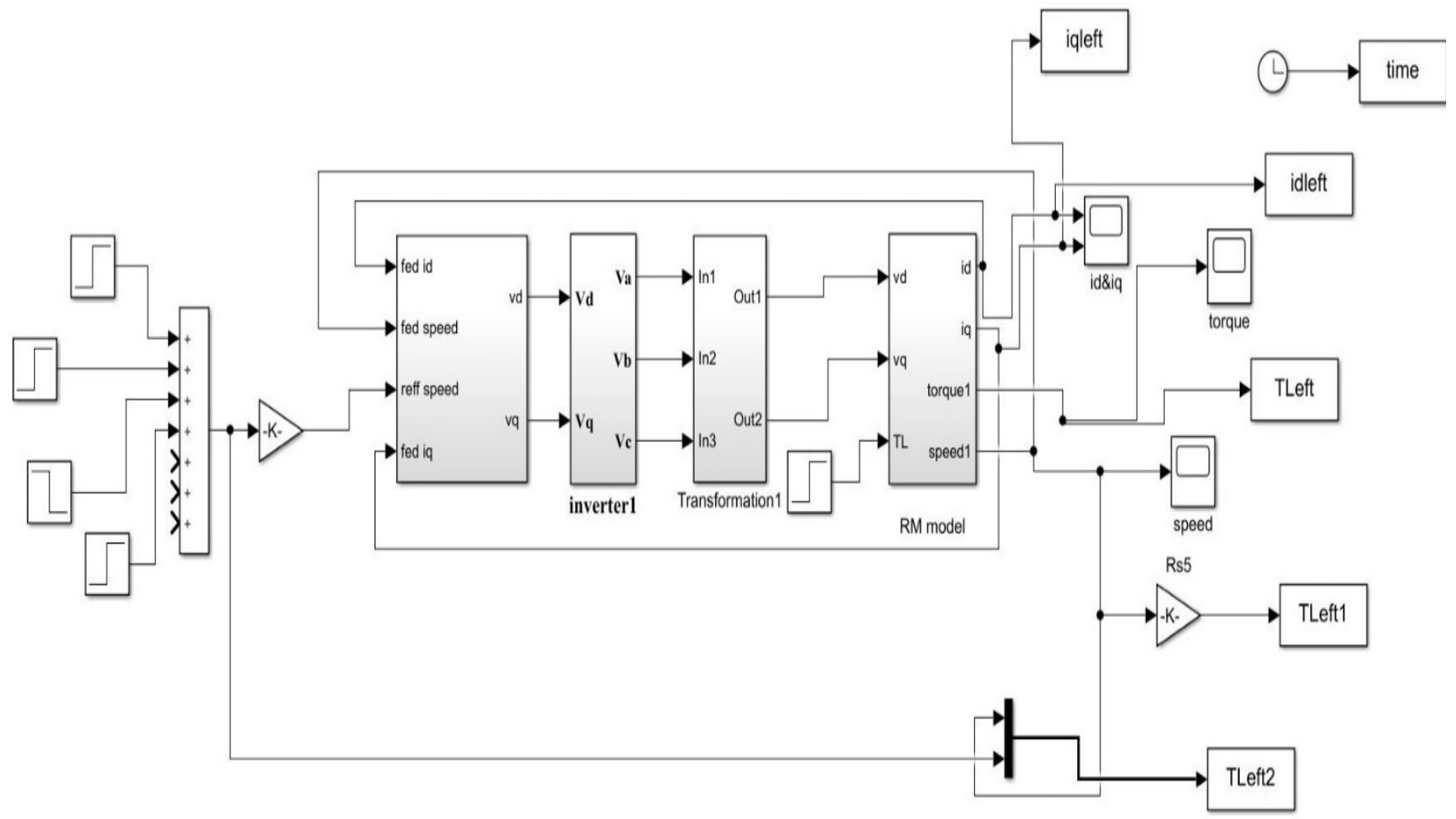

Fig.5 Motor drive system and controller

Table 1

PID algorithm parameters

\begin{tabular}{lccccccc}
$\begin{array}{c}\text { Controller } \\
\text { type }\end{array}$ & \multicolumn{3}{c}{$\begin{array}{c}\text { Speed } \\
\text { Controller } \\
\text { Parameters }\end{array}$} & q-axis & \multicolumn{2}{c}{ d-axis } \\
\hline Parameters & $\mathrm{KP}$ & $\mathbf{K}_{\mathrm{I}}$ & $\mathrm{K}_{\mathrm{d}}$ & $\mathbf{K}_{\mathbf{3}}$ & $\mathrm{K}_{\mathrm{P}}$ & $\mathbf{K}_{\mathrm{I}}$ \\
Values & 40 & 10 & 1 & 22 & 1200 & 10 \\
\hline
\end{tabular}

Table 2

The values of PSO parameters

\begin{tabular}{lc}
\hline PSO Parameters & Value \\
Maximum iteration number & 50 \\
Size of the swarm & 50 \\
Dimension & 20 \\
PSO parameter $\mathbf{c}_{\mathbf{1}}$ & 1.2 \\
PSO parameter $\mathbf{c}_{\mathbf{2}}$ & 1.2 \\
Wmax & 0.9 \\
Wmin & 0.2 \\
\hline
\end{tabular}

Table 3

PID Parameters Tuned Using PSO

\begin{tabular}{|c|c|c|c|c|c|c|}
\hline $\begin{array}{l}\text { Controll } \\
\text { er type }\end{array}$ & P & $\begin{array}{l}\text { Spee } \\
\text { ntro } \\
\text { rame }\end{array}$ & & q-axis & & \\
\hline Parameter & $\mathrm{KP}$ & $\mathbf{K}_{\mathbf{I}}$ & $\mathbf{K}_{\mathrm{d}}$ & $\mathbf{K}_{3}$ & $\mathrm{KP}$ & $\mathbf{K}_{\mathrm{I}}$ \\
\hline Values & 200 & 8.8 & 0.749 & 20.879 & 2130 & 9.8 \\
\hline
\end{tabular}

Table 4

SynRM model values

\begin{tabular}{lcc} 
Functions & Value & Measuring Unit \\
\hline Output power & 46 & $\mathrm{~kW}$ \\
Maximum Speed & 3000 & $\mathrm{RPM}$ \\
Operation frequency & 100 & $\mathrm{~Hz}$ \\
Efficiency at full load & $94.8 \%$ & - \\
Current & 103 & $\mathrm{~A}$ \\
Torque & 144 & $\mathrm{Nm}$ \\
Torque Ratio & 1.6 & - \\
\hline
\end{tabular}

Figure 6 shows the quadrature and direct axis current components of the synchronous reluctance motor when it works at no load. Here, the motor operates at half speed of rated speed, i.e. $1500 \mathrm{rpm}$, and the frequency of the voltage applied to the motor is $25 \mathrm{~Hz}$. The current drawn by the motor from the grid will be the vectorial sum of these two currents.

Figure 7 shows the speed graph of the motor when works at no load. Motor speed is oscillated and fixed to normal operation after approximately one sec. Although the motor is no loaded, the oscillation values are quite high and it took a long time for the motor to reach operating speed. Figure 8 shows the torque graph of the motor depends on the time. As it can be seen from the figure, there are large oscillations for the first one sec. Motor makes large oscillations even when it works at no load. This will cause large knocks and noise for loaded operation. These graphs prove that a control technique should be used. 


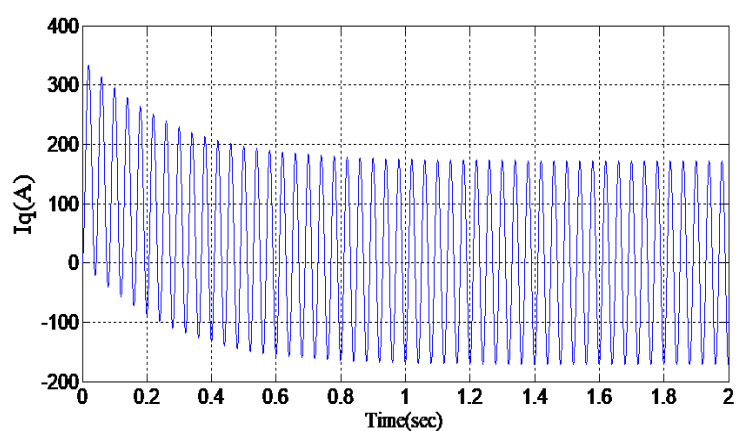

(a)

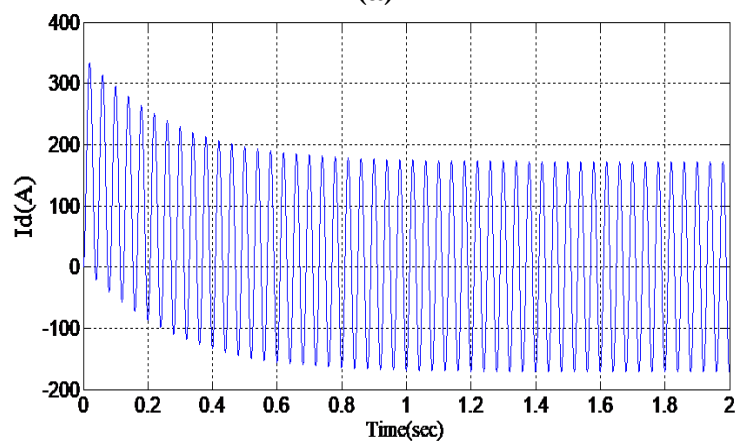

(b)

Fig.6 (a) Motor quadrature axis current, (b) Motor direct axis current at no load condition

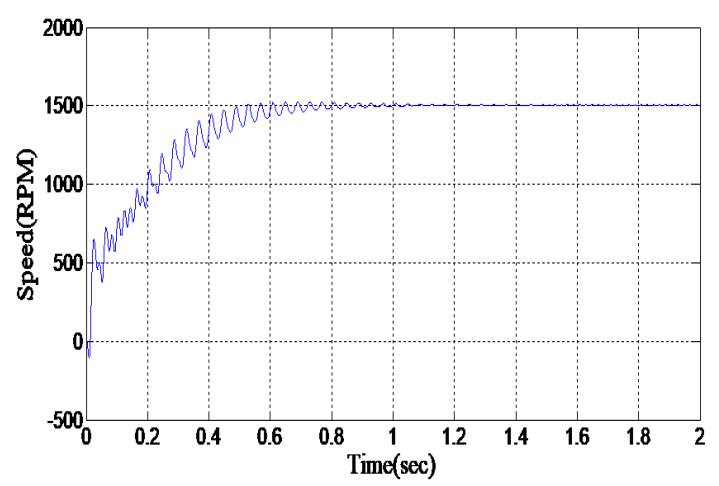

Fig.7 Motor speed at no load condition

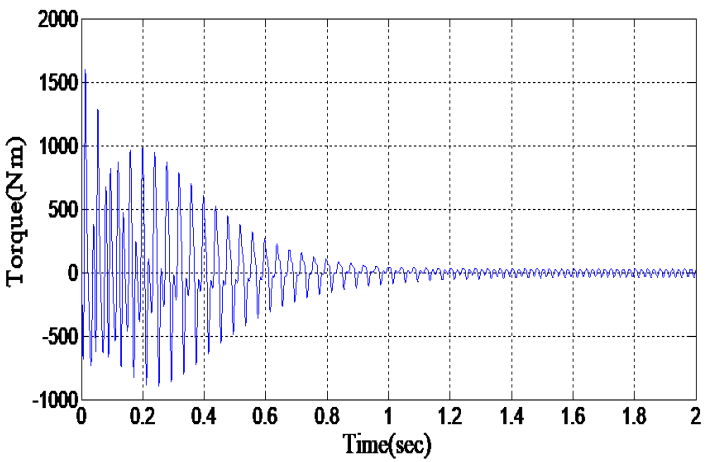

Fig.8 Motor torque at no load condition

Figures 9 (a) and (b) show speed-time graphs obtained with drive systems using cascade controller and PSO tuned controller, respectively. In the cascade control system, there is a deviation of approximately $2 \%$ from the reference speed even after 2 secs (Fig. 9(a)). This means 20 rpm at the actual speed, which is a huge deviation. Although there are some deviations in the first 2 secs in the system using PSO tuned controller, the deviation decreased by 10 times compared to the cascade system at the end of 2 secs (Fig. 9(b)). However, on the PSO tuned controller, the response is slower than the cascade controller. In Figure 9 (a), the speed closes the reference value within 70 msec, while in Figure 9 (b) the speed closes approximately within $180 \mathrm{msec}$.

Figures 10 (a) and (b) show the torque obtained from the motor for the cascade controller and the PSO tune controller, respectively. As it can be seen from the figures, when the PSO tuned controller is used, the torque obtained is approximately doubled.

In Figure 11, the motor is loaded with $10 \mathrm{~N}$ after it works at no load for 0.8 sec. The no load reactions were explained in the previous paragraph. As it can be seen from the figure, there are speed changes in both controller systems after the motor is loaded. While the speed in the cascade system decreases, the speed increases in the PSO tuned system. However, the speed change is lower in the PSO tuned system.

Figures 12 (a) and (b) show the torque curve for cascade and PSO tuned controllers, respectively, no load condition for the first $0.8 \mathrm{sec}$, and loaded with $10 \mathrm{~N}$ load. Looking at the initial sections of the figures, it is seen that the settling time in the cascade system is around 100 msec, whereas it is around $40 \mathrm{msec}$ in the PSO tuned system. Similarly, after loading, the torque changes rapidly in the PSO tuned system, whereas this change is slower in the cascade system. In addition, the obtained torque in the PSO tuned system is higher than the cascade system.

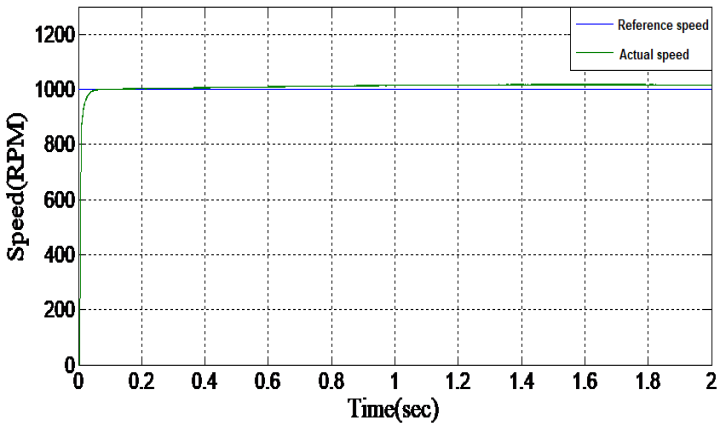

(a)

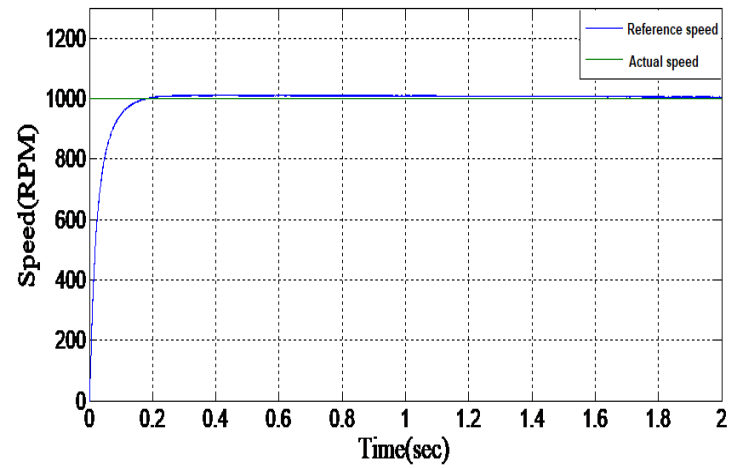

(b)

Fig.9 Speed values versus the time for 1000 RPM reference (a) with cascade controller, (b) with PSO tuned controller 


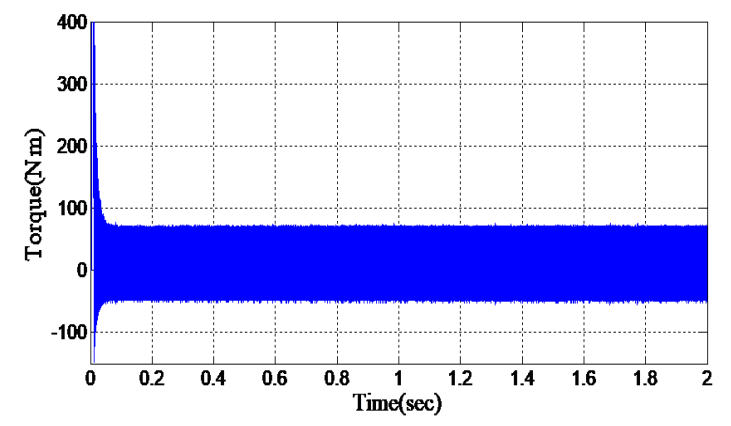

(a)

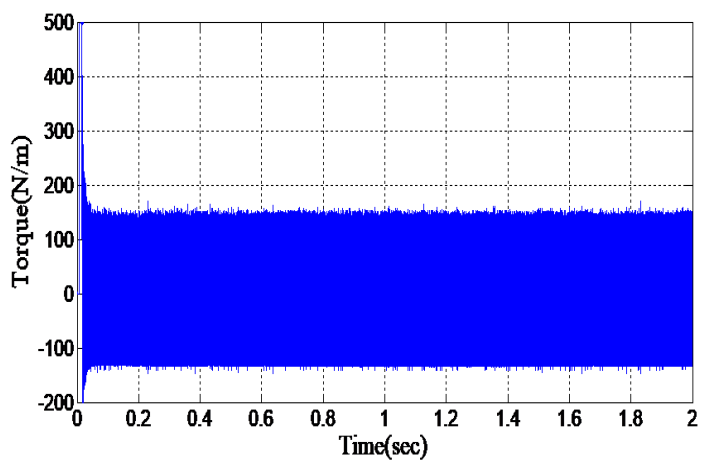

(b)

Fig. 10 Torque values versus the time for 1000 RPM reference speed (a) with cascade controller, (b) with PSO tuned controller

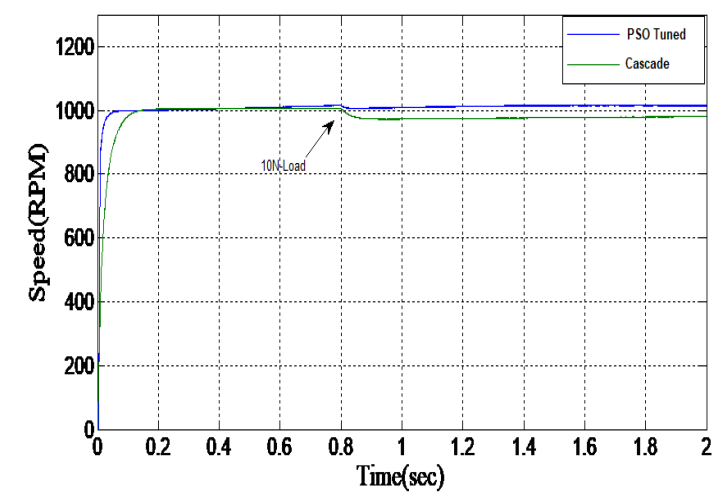

Fig. 11 Speed values versus the time for 1000 RPM reference and $10 \mathrm{~N}$ load at $0.8 \mathrm{sec}$ applied to cascade and PSO tuned controllers

Figure 13 shows the speed graph of the motor in cascade and PSO tuned systems for different reference speed values. Although the response is faster in the cascade system, the error rate is quite high compared to the reference speed values. Compared with the PSO tuned system, the error rate in the cascade system is 10-20 times higher. This result reveals that PSO tuned system is a reliable method.

Figures 14 (a) and (b) show the obtained torque graphs for the cascade controller and the PSO tuned controller, respectively, with increasing reference speed values every 250 msec. As it can be seen from the figures, the instantaneous increase in torque during speed changes is approximately two times higher in the cascade system compared to the PSO tuned system. This instantaneous increase in torque will result in knocking and physical deformation of the motor.

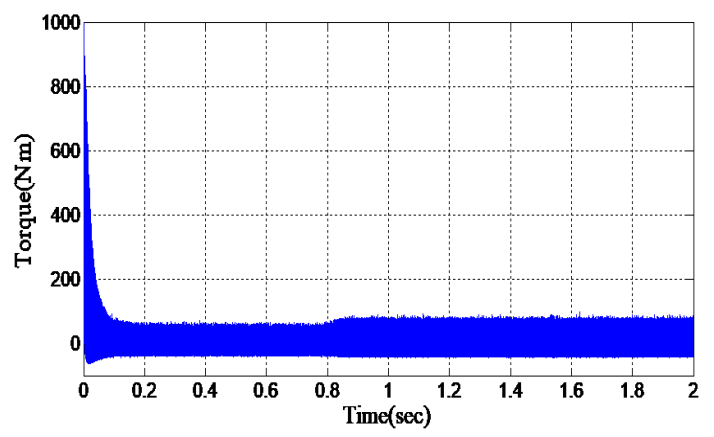

(a)

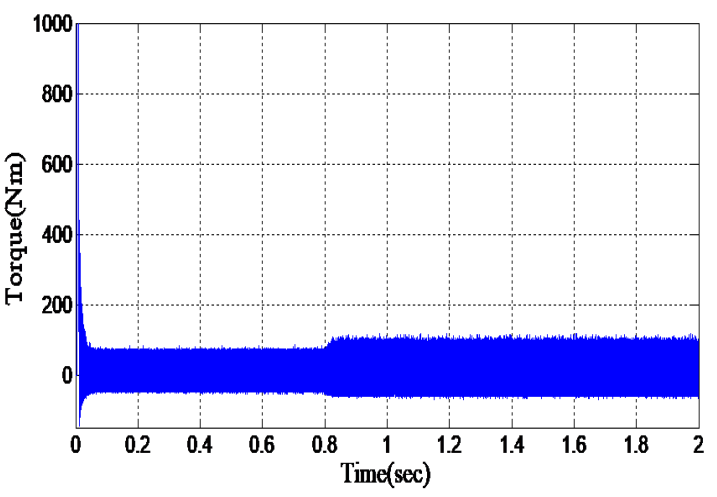

(b)

Fig. 12 Motor torque for 1000 RPM reference speed and $10 \mathrm{~N}$ load at $0.8 \mathrm{sec}$ applied to (a) Cascade controller, (b) PSO tuned controller

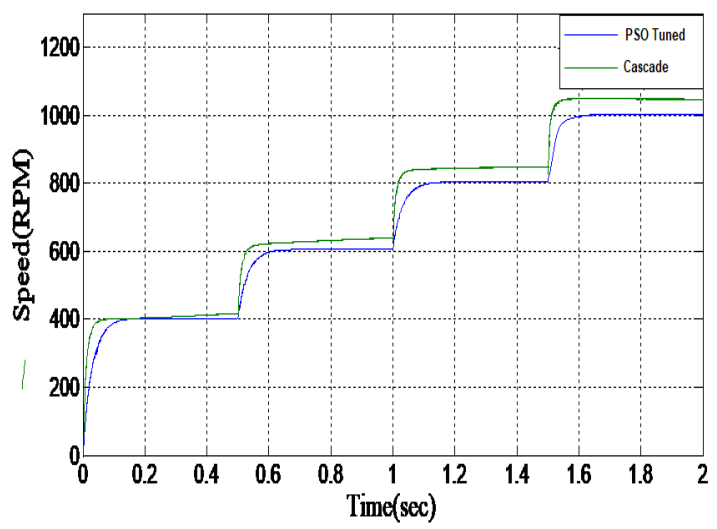

Fig. 13 Motor speed for step reference speed applied to cascade and PSO tuned controllers

The results show that the cascade controller with manually tuning parameters needs more time to back to reference speed value when applying the load to the motor in the other hand the PSO tuning parameters controller shows a major enhancement in the speed response and almost the load effect has no effect on the speed response. As a result, the PSO algorithm gives a major improvement in the speed and torque response of the motor when operated at different operation conditions. 


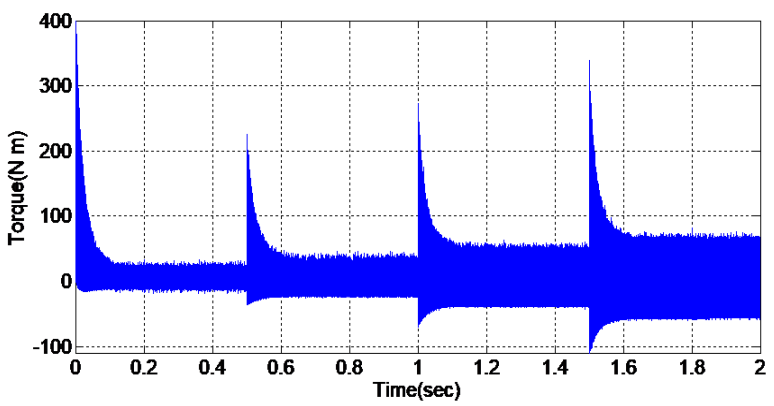

(a)

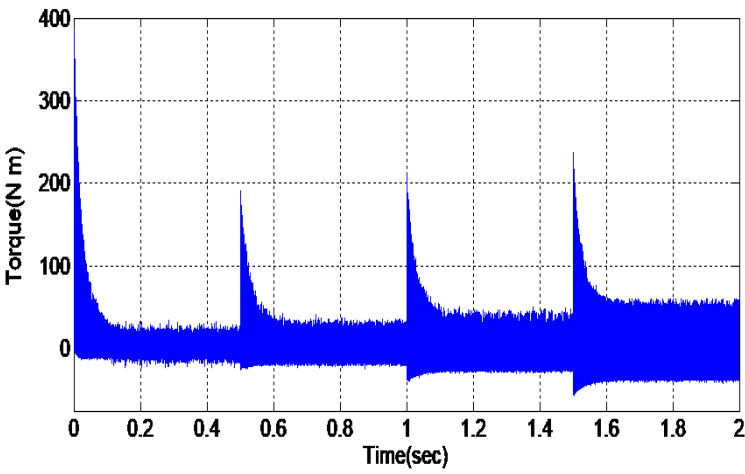

(b)

Fig. 14 Motor torque for step reference speed applied to (a) Cascade controller, (b) PSO tuned controller

\section{Conclusion}

This paper has concerned the simulation and control of the synchronous reluctance machine drive systems using Matlab/Simulink environment. The main motivation was due to a large number of SynRM advantages. In this paper, the vector control by depending on space vector pulse width modulation is used to control motor speed. The cascade controller is very difficult to tune manually and the loop intersection is the main cause of that difficulty. Particle Swarm Optimization (PSO) is a very suitable algorithm to tune the controller parameters. According to the PSO parameters, system performance is improved. The over shoot ratio is around $1.4 \%$ for the cascade controller and less than $0.1 \%$ for the PSO tuned controller. Similarly, the settling time is $1.26 \mathrm{sec}$ for cascade controller and $0.04 \mathrm{sec}$ for PSO tuned controller.

\section{Acknowledgments}

This work has been supported by Research Fund of the Aksaray University. Project Number: 2018-062.

\section{Nomenclature}

\begin{tabular}{|c|c|}
\hline $\mathbf{L}_{\mathbf{d}}$ and $\mathbf{L}_{\mathbf{q}}$ & $\begin{array}{l}\text { : the direct and quadratic axis winding self- } \\
\text { inductance }(\mathrm{H}) \text {. }\end{array}$ \\
\hline $\mathbf{R}_{\mathrm{s}}$ & : $\quad$ the stator winding resistance in $\operatorname{ohm}(\boldsymbol{\Omega})$ \\
\hline$\omega_{r}$ & $\begin{array}{l}\text { the rotor angular speed in radian per second } \\
(\mathrm{rad} / \mathrm{sec}) \text {. }\end{array}$ \\
\hline $\mathbf{T}_{\mathbf{e}}$ & $\begin{array}{l}\text { : the electromagnetic torque of the SynRM in } \\
\text { (N.M). }\end{array}$ \\
\hline $\mathrm{P}$ & $\begin{array}{l}\text { the number of poles is pairs of the motor and } \\
\text { load }\end{array}$ \\
\hline
\end{tabular}

J $\quad$ : the moment of inertia coefficient of motor in kilogram square meter $\left(\mathbf{K}_{\mathbf{g}} \mathbf{M}^{2}\right)$.

TL : the load torque to the motor in newton meter (N.M).

B : the viscous friction coefficient of the motor.

Ts : represent the sampling period.

$\mathrm{Tz} \quad$ : the switching frequency

$\mathbf{T}_{\mathbf{a}}, \mathbf{T}_{\mathbf{b}}$ and $\quad: \quad$ represent the switching period.

$\mathbf{T}_{\mathbf{o}}$

$\mathbf{m}_{\mathbf{a}} \quad$ : represent the modulation index of the SVPWM inverter

$\mathbf{V}_{\mathbf{d c}} \quad: \quad$ the DC source voltage in volt

y(i) : the model output

D(i) : the wanted output

$\mathrm{n}$ : the actual speed.

$\mathbf{n}_{\text {ref }}:$ the reference speed

$\mathbf{w}_{\text {min }} \quad: \quad$ the initial weight

$\mathbf{w}_{\max } \quad:$ the final weight

iter $_{\max } \quad:$ the maximum iteration number

\section{References}

Adlya, A.A. and Huzayyin A. (2019). The impact of demagnetization on the feasibility of permanent magnet synchronous motors in industry applications. Journal of Advanced Research, 17, 103-108.

Bayındır, R. and Vadi, S. (2017). A Web-Based Educational Tool for Simulation of Reactive Power Compensation with Synchronous Motor. Journal of Polytechnic, 20(1):61-69.

Alkhafaji, M.A. and Uzun, Y. (2018). Design, simulation and analysis of synchronous reluctance motor. The International conference on innovative research in Science Engineering \& Technology (IRSET), Belgrade, Serbia

Bouloukza, I., Mordjaoui, M., Kurt, E., Bal, G. and Ökmen, C. (2018). Electromagnetic design of a new radial flux permanent magnet motor. Journal of Energy Systems, 2(1):13-27.

Abdul-hassan, K. M., \& Kahdum, S. A. (2016). Simulation of Speed Control for Synchronous Reluctance Motor Based on Tuning Cascaded pid Controller with pso Algorithm. ThiQar University Journal for Engineering Sciences, 7(2), 115

Consoli, A., Russo, F., Scarcella, G. and Testa, A. (1999).Low- and Zero-Speed Sensorless Control of Synchronous Reluctance Motors. IEEE Transactions on Industry Applications, 35 (5): 1050-57.

Effatnejad, R., Bagheri, S., Farsijani, M., \& Talebi, R. (2013). Economic Dispatch with Particle Swarm Optimization and Optimal Power Flow. International Journal on Technical and Physical Problems of Engineering (IJTPE), 5(14): 9-16.

Fellani, M.A., and Abaid, D.E. (2010) Matlab/Simulink-Based Transient Stability Analysis of a Sensorless Synchronous Reluctance Motor. World Academy of Science, Engineering and Technology International Journal of Electrical and Computer Engineering, 4(8): 1230-34.

Fellani, M. A. and Abaid D.A. (2010) Matlab / Simulink-Based Transient Stability Analysis of a Sensorless Synchronous Reluctance Motor, 4(8): 1364-68.

Fellani, M. A. and Abaid, D.E. (2013). Modeling and Simulation of Reluctance Motor Using Digital Computer. International Journal of Computer Science and Electronics Engineering 1(2):148-52.

Fratta, A., \& Vagati, A. (1992). A reluctance motor drive for high dynamic performance application. IEEE Transactions on Industry Applications, 28(4): 873-879.

Gupta, A., \& Kumar, S. (2012). Analysis of Three Phase Space Vector PWM Voltage Source Inverter for ASD's. International Journal of Emerging Technology and 
$\mathrm{P}$ a g e 176

Advanced Engineering, 2(10): 163-168.

Hansen, A.D. and Michalke, G. (2008) Modelling and Control of Variable-speed Multi-pole Permanent Magnet Synchronous Generator Wind Turbine, Wind Energy, 11:537-554.

Huang, H. P., Jeng, J. C., Chiang, C. H., \& Pan, W. (2003). A direct method for multi-loop PI/PID controller design. Journal of process control, 13(8): 769-786.

Rahimian, M., \& Raahemifar, K. (2011, May). Optimal PID controller design for AVR system using particle swarm optimization algorithm. IEEE Canadian conference on electrical and computer engineering (CCECE), 337-40.

Rambabu, C. H., Obulesh, Y. P., \& Saibabu, C. H. (2011). MultiObjective Optimization Using Evolutionary Computation
Techniques. International Journal of Computer Applications, 27(11): 19-25.

Soni, Y. K., \& Bhatt, R. (2013). Simulated Annealing Optimized PID Controller Design using ISE IAE IATE and MSE Error Criterion. International Journal of Advanced Research in Computer Engineering \& Technology, 2(7): 2333-36.

Zheng, J., Huang, S., Rong, F., and Lye, M. (2018). Six-phase space vector PWM under stator one-phase open-circuit fault condition. Energies, 11(7):1796. 